\title{
A Theoretical Basis for Learning in Massive Multiplayer Virtual Worlds
}

\author{
Stephen W. Harmon \\ Georgia State University
}

\begin{abstract}
One of the most compelling affordances of information communications technologies for education is the combination of social interaction, simulation, and creative play offered by online games. Although massive multiplayer online games have been in existence for some time, only with the widespread adoption of highspeed Internet access has their potential has begun to be realized. This article focuses on the affordances of massive multiplayer virtual learning environments (MMVLES) for education by examining the benefits of a theoretical understanding of learning, and then discussing the concept of affordances. An exploration of the theoretical framework supporting learning in MMVLEs as seen through the lens of selected learning theories is also given.
\end{abstract}

Keywords: Virtual Learning Environments, Constructionism, Social Constructivism, Situated Cognition

\section{Introduction}

Nearly 20 years ago Gary Larson, the creator of the Farside comic strip, authored a cartoon that depicted a small child glued to the front of his television set engrossed in a video game. Standing behind him, his loving and hopeful parents imagine the help wanted section of a newspaper 15 years in the future. The imagined help wanted ads list several variations of jobs needing video game players and offer very attractive salaries. What made this comic funny in 1990 was the ludicrousness of the idea that anyone would ever hire someone because of his or her expertise in playing video games. Today, the comic does not seem nearly as amusing, because the premise has more or less come to be true. At the time of this writing there are hundreds if not thousands of young men and women who are earning their living playing video games. Entire factories of Chinese gold farmers play long hours of World of Warcraft earning virtual gold which they sell for real money (Barboza, 2005).

The senior director of engineering for Yahoo.com owes his job to playing World of Warcraft, at least in part. One of the reasons he was given the job was because of his expertise in managing people, which he gained as the head of a guild in the online game (Brown \& Thomas, 2006). The same skills he used to manage a large and diverse group of players to accomplish various in-game goals and missions, apply directly to his position managing a large and diverse group of employees, who are seeking to achieve the goals and missions of the organization. Video game sales in the United States in 2007 accounted for 9.5 billion dollars (Entertainment Software Association, http://www.theesa.com/facts/salesandgenre. asp); almost on par with the gross revenue of the motion picture industry (http://arstechnica. $\mathrm{com} /$ news.ars/post/20080124-growth-of- 
gaming-in-2007-far-outpaces-movies-music. html). Clearly, video games have begun to come into their own as an important and respected part of society. As new generations of gamers grow up and assume positions of leadership and responsibility in society, the importance and prevalence of video games seem logical.

Yet, as with most other technologies, video games continue to lag behind in education. Although there are some good examples of the use of video games for education, these are typically small-scale and lack the high production values of games created for entertainment. This should not be surprising because virtually all new technologies seem to take longer to be adopted by education. In the case of video games however, it does seem that they are making inroads into the education and training communities much more rapidly than similar technologies have in the past. Therefore, educators need to have a positive influence on educational video games and ensure that they are built in accordance with what we know about learning and instruction.

To that end, this paper seeks to provide a theoretical basis for the development of learning in educational video games. In particular, the paper focuses on learning in a particular type of video game, that of the massive multiplayer virtual world. The paper suggests the creation of a type of virtual environment specifically for education, a massive multiplayer virtual learning environment (MMVLE). A massive multiplayer virtual learning environment is a virtual space that combines the simulated world and multiplayer aspects of video games with specific intentional instructional strategies. These learning virtual environments seem at present to have the greatest potential to achieve real and meaningful impact in education. These environments take advantage of the ability of the Internet to bring together thousands, even millions of users, and to do so in a virtual world that emulates authentic learning contexts. I will discuss several ideas that provide a sound basis for decision making regarding the development of these environments for education. Specifically, I will provide a rationale for thinking about theory in general. I will then discuss the concept of affordances and how this concept relates to technology. Following that, we will look at several learning theories that seem to apply well to massive multiplayer virtual worlds. In particular, these are constructionism, social constructivism, and situated cognition. Additionally, we will explore the ramifications of pleasure in learning and identity exploration as they relate to learning in massive multiplayer virtual worlds.

\section{Theory}

So why should we care about theory? Having a well grounded theoretical perspective is essential when designing instruction in new and complex situations. Often I have heard of corporate trainers who have over 20 years experience designing training who fail miserably when faced with the challenges of a new content area or a new type of population of students. These trainers have not actually had 20 years experience designing training; the trainers in these situations have typically had one year experience designing training, 20 times. In other words, these trainers have designed the same lesson over and over again. The archetypal trainer may be an expert at one technique or instructional strategy, but because he or she lacks understanding of the foundations of that strategy he or she is not able to modify the strategy effectively or know when to apply new strategies.

Consider the difference between a cook and a chef. A cook can expertly follow a recipe. $\mathrm{He}$ or she can gather the ingredients, measure them out, and mix them together to create a set menu. Moreover, he or she can do this with 
only minimal variance in the result time after time. But, a cook struggles in creating a new recipe, working with new ingredients, or trying to please a group of diners with tastes different than that to which he or she is accustomed. The cook lacks the foundational understanding necessary to break new culinary ground. The chef on the other hand does understand the foundations of food and cooking. He or she not only knows what all the ingredients in a recipe are, he or she also understands why those ingredients go together and how they interact. The chef can easily substitute ingredients, or use those ingredients in new ways to obtain different effects. Because the chef understands the foundations of cooking, the chef is not limited to a recipe that someone else has already created. Instead, the chef can create new recipes as needed to best suit the demands of the circumstances.

The same holds true for designers of learning environments. Unless the designer understands the theory behind the instructional strategies used in an environment, then he or she is limited to only one set of instructional strategies that suit only one set of circumstances. For example, many aspiring instructional designers find the Dick and Carey (1990) model of instructional design limiting because of its high degree of specificity. But, if these designers had a greater understanding of the learning theories underlying the model then they would be better able to adapt the model to different situations, sometimes emphasizing one aspect or de-emphasizing another. If one understands the foundations of instructional design then one need not merely follow a single model by rote, but instead is prepared to adapt that model to suit specific needs or even to create a new model.

Understanding the foundations of learning becomes particularly important when working in a new environment. Virtual learning environments made possible by massive multiplayer games represent just such a condition. While we do have a reasonable understanding and set of prescriptions for learning in face-to-face classrooms, learning in simulations, and learning in games, we have not yet developed a robust understanding of how best to facilitate learning when all three are, to some extent at least, combined. Aldrich (2005) defines an educational simulation as the intersection of a simulation, a game, and pedagogy. While that definition is useful, it seems lacking in two ways. First, an educational simulation need not have a game element. Whereas a simulation is a representation of reality, an educational simulation is a representation of reality coupled with instruction that is designed to teach students to manage that reality; a game element is not required. It seems more apropos that the intersection of simulations, games, and pedagogy be called a virtual learning environment (VLE). As such, a VLE would be a representation of reality (simulation) incorporating instructional strategies (pedagogy) and an element of play (gaming) designed to facilitate the achievement of an intended learning outcome. Figure 1 below, shows this adaptation of Aldrich's model.

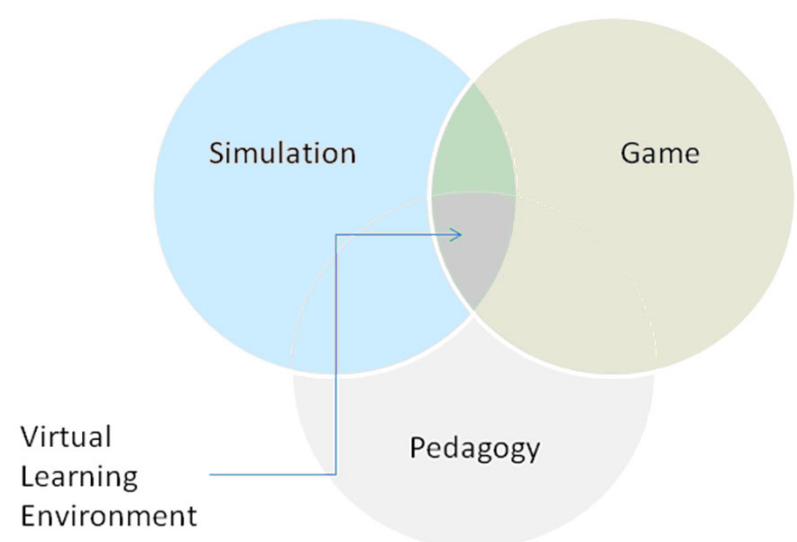

Figure 1: The design space for virtual learning environments 
Note that this model only shows a virtual learning environment, and not a massive multiplayer virtual learning environment (MMVLE). The second way Aldrich's (2005) definition is lacking is in capturing the collective and collaborative nature of multiplayer games. Social construction of knowledge is an important affordance of these technologies for education. Thus, a fourth element is needed in this model to illustrate the impact of the massive social interactions made possible by the Internet in virtual learning environments. This element transforms a Virtual Learning Environment into a Massive Multiplayer Virtual Learning Environment. Figure 2 presents a model of an MMVLE.

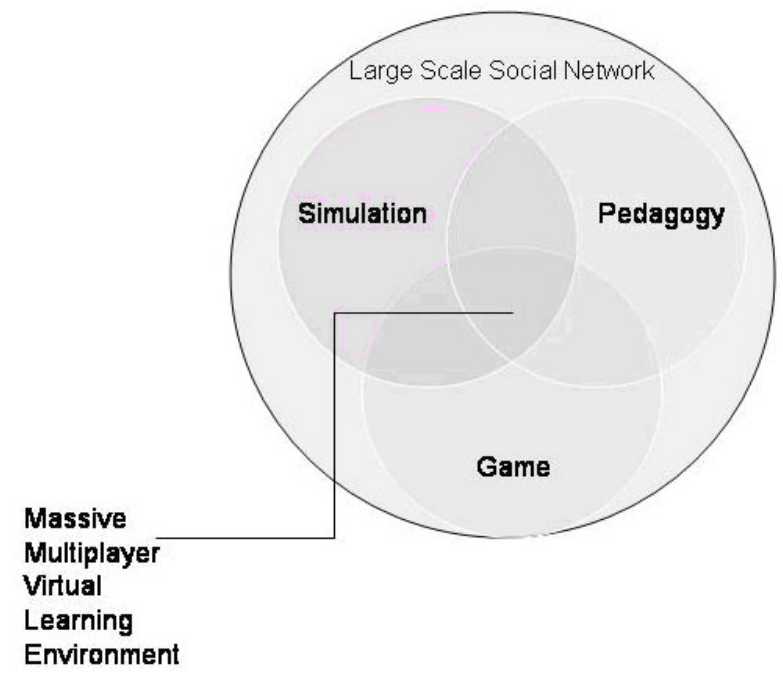

Figure 2: The design space for Massive Multiplayer Virtual Learning Environments

The difference between a VLE and an MMVLE is that while a VLE can be used with a single learner working alone, an MMVLE requires the interaction of a large number of learners working collectively. This context of large scale social interaction provides a new opportunity for learning that has not been easily accessible before now. As noted below, the massive multiplayer aspect of MMVLE's provide a capability for interaction that allows us to implement the ideas of Vygotsky's (1978)
Social Constructivist theory of learning in a way that was not possible only a few years ago. This notion of taking advantage of the unique capabilities of MMVLE's for education is an important one, and is known as the concept of "affordances."

\section{Affordances}

The creation of massive multiplayer virtual learning environments (MMVLEs) is a relatively recent innovation made possible by computer-mediated communication technologies and the Internet. The Internet creates the possibility for making these environments. Or, to state it another way, the Internet affords us the ability to make these environments. This concept of affordances is an important one. Gaver notes "As a means for analyzing technologies, affordances should be useful in exploring the psychological claims inherent in artifacts... and the rationale of designs", (1991, p.83). Simply put, an affordance is a capability for action inherent in an object or technology (Gibson, 1977; Norman 1988). Well-designed objects intuitively suggest what these capabilities may be. In objects that are not so well-designed, or are perhaps highly complicated, the capabilities for action may not be so obvious (of course, one might also argue that highly complicated objects are by definition not so well designed). Consider a claw hammer. It fairly intuitively affords possibilities for striking objects, or for prying them apart. Somewhat less intuitively, a claw hammer could also be used as a back scratcher, a plumb bob, or perhaps a very short walking stick.

Determining the affordances of basic physical objects is often simpler then determining the affordances of more conceptually challenging objects such as a computer or software. I doubt that any of the great thinkers in history prior to the $19^{\text {th }}$ century 
would have had any idea what to do with a modern computer if someone went back in time and presented them with one. They would have had no frame of reference with which to begin to consider the affordances of such a device. Indeed, even in our modern society, we are still struggling as a whole somewhat in determining, or at least embracing the affordances of computers. Particularly in public education, we tend to see computers as some sort of cross between a typewriter and an adding machine. Sloane (1999) refers to this tendency to see new media in old ways as "medial haunting." Only with the advent of the Internet, and perhaps multimedia, have we begun to see the computer as something more than that. We now seem to be in an age where we are beginning to grasp and take advantage of the affordances of the computer as a communications device. E-mail, instant messaging, Internet telephony, and videoconferencing are just some of the ways in which this realization is becoming manifest.

Regrettably, as bad as we are as a society of grasping the affordances of computers and the Internet for communications, we are even worse at realizing the affordances of computers and the Internet for education. Several years ago a large computer company produced a promotional video showing the "future of education." The video featured a classroom with all the children sitting in neat rows and on every desk a computer with a flat screen monitor. On every monitor, was the same image of a teacher giving a lecture. Sadly, the promotional video was all too prescient. We have used computers and other modern communications technologies to perpetuate instructional strategies of dubious efficacy and limited creativity. Today in education we do seem to be moving somewhat beyond the concept of a computer as a calculator or typewriter, and even somewhat beyond the concept of a computer as a television. The success of rapid Internet search technologies such as that offered by Google, has led us to also consider the computer to be something of a personalized library. While this is a step forward, it is not a very big step.

I suggest we consider the affordances of massive multiplayer virtual learning environments. In particular, we should look at the affordances of these environments for supporting some specific learning and instructional theories. I hope that by exploring the affordances of technology with respect to some theories of learning, we will be able to begin to design environments that purposely take advantage of both the technology and the theory. We have for too long designed instructional technologies around instructional strategies without considering the underlying theories of learning. Drill and practice, immediate feedback, and individualized branching instruction can all be good instructional practices. But, they can also be limiting, particularly in light of new and emerging technologies. We used those strategies in the past with computerbased instruction, partly because they were well within the limits of the technology, and partly because they were within the limits of our creativity. We now have the opportunity, afforded to us by the technology, of breaking those limits.

\section{Constructivism and Constructionism}

One way in which we could break those limits is to consider the foundations of learning rather than specific strategies of instruction. There is perhaps no more of a foundational aspect of learning than that of constructivism. For those readers not familiar with the topic, constructivism is a branch of metaphysics, that part of philosophy that deals with the question of what is reality. Constructivism is most often contrasted with positivism or objectivism. Where positivism or objectivism suggests 
that reality exists apart from the knower, constructivism holds that reality is a construct of the knower's mind. If a tree falls in the forest and no one is around to hear it, does the tree make a sound? The positivist would say of course. The constructivist would say of course not, for if no one has conceived of that tree in that forest, it does not exist. Radical constructivism such as that may be a difficult concept to grasp. Moderate constructivism, however, is easier to understand and has come to influence much of education today. A moderate constructivist holds that whether or not reality exists apart from the knower, our perceptions of reality are indeed a product of our minds. This conceptualization erases the tabula rasa concept that governed our theories of learning for millennia. Instead of being a blank slate, the mind is a complex network, and learning is a matter of not just constructing new information, but also of fitting that information in with everything else we know. If not reality in itself, then at least our perception of reality is constructed in our minds. Today, many learning theories assume a constructivist perspective.

Constructionism is a subdomain of constructivism. It advocates the idea of creating something as an instructional strategy. In the words of its major proponent:

Constructionism--the $\mathrm{N}$ word as opposed to the V word--shares constructivism's connotation of learning as "building knowledge structures" irrespective of the circumstances of the learning. It then adds the idea that this happens especially felicitously in a context where the learner is consciously engaged in constructing a public entity, whether it's a sand castle on the beach or a theory of the universe (Papert \& Harel, 1991; p.1).

This idea of learning by building is a powerful one. We learn best when we create something. Massive multiplayer virtual environments offer an ideal setting for implementing a constructionist pedagogy. One can build anything one desires. Whereas in a real classroom it is difficult to provide all of the materials that students may need to actually build things, much less provide these materials in contexts which are meaningful to the course content. In a virtual environment there is no cost and no resource burden associated with building whatever one can conceive. Importantly, there is also no danger involved in constructing massive virtual edifices. In the real world, students are limited by lack of access to the material, tools, and the know-how needed to create interesting and complex structures. But, in the virtual world the material, tools, know-how, and skills are provided or scaffolded for the student as needed. Virtual learning environments afford us the ability to implement constructionism in a richer way than ever before.

Note that Papert and Harel (1991) say constructionism works best when the construction happens in public. The massive multiplayer aspect of virtual learning environments provides just such a public forum. Not only can the students build whatever they can conceive clearly enough, they build it in plain view of all the other students and of the rest of the world. Students take pride in the development of these public structures. They are therefore willing to push themselves farther in order to do a better job. Even more so, to do a better job learners are often motivated to seek additional information and skills that they may need to complete the project. This idea of pushing themselves further dovetails nicely with Vygotsky's (1978) zone of proximal development, the idea that students learn best when their learning is scaffolded by someone who already possesses the knowledge the students are seeking to obtain. Massive multiplayer virtual learning 
environments offer a wide range of guides and mentors that can assist students in seeking to accomplish that which would they could not accomplish alone. MMVLE's afford us the ability to implement constructivist and constructionist learning design in new and potentially powerful ways.

\section{Social Constructivism}

Vygotsky (1978) also provides us with another foundational learning theory, that of social constructivism. This is the idea that learning occurs in social contexts through dynamic interaction with teachers, peers, and content. Certainly, one can learn alone, but learning may be more efficient when done collaboratively. Vygotsky's classic example is that of an infant learning to point. Babies do not learn to point at an object by having someone tell them what extending one finger toward an object means. Instead, they learn by observing the reactions of those around them when they do happen to point at objects. As the baby points at something, say a stuffed animal across the room, the baby may notice that the adults turn to look at the stuffed animal. Over time, the baby begins to associate the act of pointing with the reaction it elicits from the adults. While Skinner (1974) might refer to this as a form of operant conditioning, Vygotsky used this pointing as an example of how learning occurs in social contexts. To briefly return to the concept of constructivism, in actual practice thinking of reality as a construct of an individual's mind does not seem to work very well. If everyone acted as though his or her individual conception of reality was totally independent of everyone else's, chaos would quickly result and society would break down. Instead, reality seems to be a shared social construct. In other words, reality is whatever we agree it is. If this is true then reality exists as a function of a collective set of minds.
Logically, learning should thus also occur as a function of a collective set of minds.

Massive multiplayer virtual learning environments afford us an opportunity to facilitate social constructivism. The environments foster interaction among small or large groups and alson allow groups to create a shared reality within the virtual world. The process of creating this reality can be messy and boisterous; two characteristics that educators have been trying to eliminate from face-to-face classrooms for years. But, in a virtual world, messiness and boisterousness are of little consequence. Cleanup is easy and noise is minimal. One concrete example of social constructivism that occurs in the virtual world is Wikipedia (www.wikipedia. org). Here, massive numbers of individuals come together to negotiate reality. If one scans the discussion pages behind an article, one will see that the process is indeed messy and boisterous. By scanning the history of any article in Wikipedia, one will generally find that the interactions of the many individuals typically lead to a richer and more consistent understanding of the topic in question. In other words, the individuals involved in creating the article learn something about that topic. Now, Wikipedia is something of an abstract virtual world in that it exists primarily as a text-based resource. Wikipedia does, however, provide an easy way to understand the same process that can occur in more graphically rich virtual worlds.

Imagine if one assigned a group of students the task of creating a system of government that is just, manageable, and most importantly, accepted by the governed. Students might succeed in doing this in a face-to-face classroom, but they would not be able to test that system of government on a large-scale. It is much easier to govern 30 people than it is to govern 300 people. Imagine though, that you 
assigned the same task to a group of students and ask them to design a system of government that would work for 30,000 people. Chances are that in successfully completing this task students would come to a richer understanding about government in general. In fact, the massive multiplayer game Tribal Wars (www. tribalwars.net) does just this every day. Players in the game are forced to self-organize into competing interest groups, some of which will eventually come to dominate the world. In this game the players, or students, socially construct a set of rules by which they will conduct and manage their activities. Games last a nonspecified amount of time, sometimes years, and involve tens of thousands of players. Over the course of the gameplay, the students develop an experience-based understanding of the benefits and drawbacks of several types of government. This understanding is not merely theoretical; it is practical and based on learning within a real context. MMVLEs afford us the ability to foster rich social interaction as a means of building learning communities and promoting social knowledge construction.

\section{Situated Cognition}

The idea of situating learning in an authentic context is referred to as situated cognition (Brown, Collins, \& Duguid, 1989). Too often, formal education occurs in an inauthentic context. Consider vocabulary learning. Children learn vocabulary at a prodigious rate when they are growing up. But, once they reach school they seem to struggle to master ten vocabulary words every week. Additionally, once they do master the vocabulary words they may attach inappropriate usages to them. Brown, Collins, \& Duguid provide Miller \& Gildea's (1987) example of "Mrs. Morrow stimulated the soup" (p. 32). This difficulty in learning vocabulary at school may be attributed in some part to the artificial context for language that the schools provide. This artificial context can produce inert knowledge; knowledge that is only useful in the classroom and has little relevance in the real world. On the other hand, learning that occurs in a real context is readily transferable to the real world and is likely to be well-integrated into the student's existing knowledge networks. One example of this is teaching students basic arithmetic in the context of shopping for groceries. The students learn about money and about addition and subtraction when they are given a set budget and asked to purchase several items in a grocery store. As they consider and reconsider which items to buy, they must solve several math problems in an efficacious fashion. Situated cognition holds that because they are doing this learning in a real context, knowledge is much more likely to be relevant to the students than if they were solving the same problem represented in a worksheet.

The downside of this approach lay in the difficulty of taking an entire class of students and putting them in an authentic context. The time and logistics involved in getting a class of students to go to the grocery store to learn math make it impractical to use as a regular instructional technique. Massive multiplayer virtual learning environments, however, afford us the ability to create simulated authentic contexts for learning. While that may sound something like an oxymoron, simulated authenticity may be a far preferable approach to the typically highly abstract context of a classroom. By using MMVLE's we can not only afford the time and resources needed to teach a subject in a real context, we can also tailor the context to the specific needs and levels of the learners. In the game World of Warcraft players must develop their characters' trade and professional skills such as herbalism and alchemy. Players can gather herbs, learn recipes to make potions using the herbs, and then make the potions and sell them on the open market. Players thus learn the basics of 
commodities exchange and the laws of supply and demand. If a player floods the market with a particular type of potion (say one that increases the character's agility) he or she soon finds that the price for that potion drops. Cartels of players can spontaneously emerge and attempt to corner the market on a particularly valuable ingredient. Complicated barter systems and banking systems emerge that allow players to purchase items on credit. In short, players in the game learn the fundamentals of economics, not by reading about them in a textbook, but by being an integral part of a virtual economy. MMVLE's afford us the ability to provide authentic contexts and problems for learning in ways not easily replicable in a face to face setting.

\section{Other Affordances}

Unlike the archetypal image of students in the dusty old economics classroom, World of Warcraft players tend to enjoy learning about economics. They take great pleasure in finding the most efficient way to create a "virtual something" that they can then sell for the greatest virtual profit. The concept of pleasure in learning is fundamental to the human psyche (Gee, 2005a). Some researchers have proposed a neurological explanation for why this may be:

We believe that the enjoyment of such experiences [learning] is deeply connected to an innate hunger for information: Human beings are designed to be "infovores." It'sa craving that begins with a simple preference for certain types of stimuli, then proceeds to more sophisticated levels of perception and cognition that draw on associations the brain makes with previous experiences. (Biederman \& Vessel, 2006, p.247)
Indeed, Biederman \& Vessel go on to propose a mechanism for the chemical stimulation of pleasure centers in the brain in response to learning. Too often, however, we manage to suck the pleasure right out of learning. One seems far more likely to hear American schoolchildren say "do I have to go to school today," than to hear "do I get to go to school today." Just the opposite is true, however, if the topic is videogames (in fact, as I have been writing this, my own children have asked me three times for permission to play video games). As a general rule, children love videogames and profess to hate school. If we accept that the act of learning itself is pleasurable, indeed that the brain is hardwired for this, then that hatred of school does not speak well for education in general.

Massive multiplayer virtual learning environments bring pleasure back to learning. They afford us the ability to make learning enjoyable for even the most recalcitrant learners. Gee (2005b) writes:

I believe that good commercial video games are by no means trivial phenomena. They are deep technologies for recruiting learning as a form of profound pleasure. They have much to tell us about what learning might look like in the future, if and when we decide to give up the old grammars of traditional schooling (Gee, 2004, p.211).

I, and many other parents, find myself having to discourage my children from playing video games. They love them. Why they love them is beyond the scope of this article, but they do. It seems straightforward then that we should be able to radically enhance the engagement of children in schools if we work to incorporate successful design elements of videogames. Up to now, doing this has been difficult largely because of various economies of scale, and 
perhaps an unwillingness to modify our educational systems. But, even if we cannot change schools, we can certainly change videogames to make them more educational. We can take advantage of this affordance to provide informal learning opportunities for students that would help prepare them for both the formal learning found in schools and for the real world.

Gee (2005a) also suggests another affordance of massive multiplayer virtual learning environments, which is the ability to create the, what he terms, "virreal." The virreal is a blending of the virtual and real. It is the projection of the learner into the virtual space of the game. The learner inhabits the game avatar, adopting its goals and objectives, and being scaffolded by prerequisite skills and knowledge programmed into the avatar by the game designers. The creation of the virreal allows the learner to undertake and achieve success in problem-solving that he or she would not have been able to solve outside of the virtual world. The virreal allows the learner to take the role of an expert in a given domain (note that this scaffolding of the student's roleplaying also meshes nicely with Vygotsky's (1978) Zone of Proximal Development). The learner can play at being a general in Tribal Wars, or a healer in World of Warcraft without having all of the skills needed for either of these professions. Playing the role of an expert is how some learning occurs already. The new chemistry student working in the lab is not a chemist. He or she is role-playing a chemist, scaffolded by a real chemist. The student lacks the skills of a real chemist, but with expert help can play the role of real chemist, and thus, gain knowledge of the domain.

Not all domains lend themselves to a realworld laboratory environment. Some are too dangerous, too costly, or too complex to create in a school. Massive multiplayer virtual learning environments afford us the ability to provide students the opportunity to roleplay experts in virtually any domain of which we can conceive. The virreal student is able to, at least to some extent, see the world as an expert sees the world, and thus, began to develop some of the thought processes of an expert. MMVLEs can help the student learn to think like a chemist, rather than to merely learn chemistry. This approach to learning fits nicely with the constructivist viewpoint. Rather than blindly superimposing a knowledge schema onto a learner's mind, we assist the learner in constructing knowledge of a domain in the same way that an expert in that domain would. The resulting knowledge construct would therefore have characteristics of an expert construct, but be tied into the novice's pre-existing knowledge in a meaningful way. MMVLEs afford us the ability to explore identities as experts in a domain, and to have fun while doing so.

\section{Conclusion}

Massive multiplayer virtual learning environments represent a new technology that affords us the opportunity to take advantage of some learning theories as we never have before. Although they are still relatively costly to build and maintain, these costs are falling and will most likely continue to do so. Already, development tools for these environments are commercially available and relatively straightforward to use. A future seems likely in which developing these environments will become easier, cheaper, and more widespread, just as has been the case with most other learning technologies before (e.g., multimedia, Web development). A future also seems likely in which it is not the development of the technology that will lag behind with respect to education, rather, the effective application of these technologies in education will be the laggard. If we are not to be doomed by our medial haunting to use 
these new technologies in old ways, then we must consider the affordances they offer that are not readily available in other media. This article has attempted to begin that consideration by looking at the affordances of massive multiplayer virtual learning environments through the lens of some learning theories. MMVLE's afford us the ability to implement constructivist and constructionist learning design in new and potentially powerful ways. They afford us the ability to foster rich social interaction as a means of building learning communities and promoting social knowledge construction. They afford us the ability to provide authentic contexts and problems for learning in ways not easily replicable in a face to face setting. And lastly, MMVLEs afford us the ability to explore identities as experts in a domain, and to have fun while doing so.

I believe these environments offer our best opportunity to take advantage of the insights of these theories. If we are able to consider learning at a more basic level and take advantage of the affordances of MMVEs for supporting the result of that consideration, then we may well be on the path of becoming chefs instead of just cooks. Now let us go stimulate our cognitive soup.

\section{References}

Aldrich, C. (2005). Learning by doing: $A$ comprehensive guide to simulations, computer games, and pedagogy in e-learning and other educational experiences. NY: John Wiley \& Sons, Inc.

Barboza, D. (2005, December 9). Ogre to slay: Outsource it to Chinese. The New York Times, Retrieved from: http://www.nytimes.com/2005/12/09/ technology/09gaming.html

Biederman, I., \& Vessel, E. A. (2006) Perceptual pleasure and the brain. American Scientist
94, 247-253.

Brown, J.S., Collins, A., \& Duguid, P. (1989). Situated cognition and the culture of learning. Educational Researcher, Jan/ Feb, 32-42.

Brown, J. S., \& Thomas, D. (2006). "You play World of Warcraft? You're hired!" Wired 14(4), 120.

Dick, W., \& Carey, L.M. (1990). The systematic design of instruction (3rd ed.). Glenview, IL: Scott, Foresman, Little, Brown.

Gaver, W.W. (1991). Technology affordances. In Proceedings of the SIGCHI conference on human factors in computing systems: Reaching through technology. New Orleans, Louisiana. 79-84.

Gee, J.P. (2004). Situated Language and Learning: A critique of traditional schooling. London: Routledge.

Gee, J.P. (2005a). Why videogames are good for the soul. Victoria, AU. Common Ground Publishers.

Gee, J.P. (2005b). Pleasure, Learning, Video Games, and Life: the projective stance, E-Learning, 2(3), 211-223. Retrieved June 26, 2008 from http://dx.doi.org/10.2304/ elea.2005.2.3.2

Gibson, J.J.(1977). The theory of affordances. In R. Shaw \& J. Bransford (Eds.) Perceiving, Acting, and Knowing, Hillsdale, N.J.: Erlbaum.

Miller, G. A., \& Gildea, P. (1987). How children learn words. Scientific American," September, 94-99.

Norman, D. (1988). The design of everyday things. New York, NY: Doubleday.

Papert, S.A., \& HarelI.(1991). Constructionism. Norwood, NJ.: Ablex Publishing.

Skinner, B.F. (1974). About behaviorism. New York: Knopf.

Sloane, S. (1999). The haunting story of J.: Genealogy as a critical category in understanding how a writer composes. In G. Hawisher, \& Cynthia Selfe (Eds.), Passions, Pedagogies, and 21st Century 
Technologies. Logan, Utah: Utah State University Press. 49-65.

Vygotsky, L.S. (1978). Mind in Society.

Cambridge, MA: Harvard University

Press.

\section{Contact the Author:}

Stephen W. Harmon, Ph.D.

Georgia State University

Email: swharmon@gsu.edu 